\title{
EDITORIAL
}

\section{The ERJ in its 21 st year of age: a smooth transition for an everlasting evolution}

\author{
A.T. Dinh-Xuan* and V. Brusasco ${ }^{\#}$
}

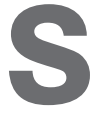

tarting a new job has never been an easy task. It is even more difficult to continue an enterprise initiated $20 \mathrm{yrs}$ ago [1], which has then been progressively built upon throughout the years by previous Editorial Boards [2-7], and finally strengthened in such a masterful manner by our predecessors [8]. But the advantage of having such a strong heritage is that it offers abundant resources [9], for which we are most grateful to the previous joint European Respiratory Journal (ERJ) Chief Editors, Peter J. Sterk and Klaus F. Rabe. By firmly establishing the ERJ among the top journals in the respiratory field $[8,9]$, they have clearly indicated the way for us, and the new Editorial team, to drive the ERJ forward and provide a constantly improving service for the international respiratory community. Before commencing on this journey, which we will continue for the next 4 yrs, let us have a look back at the paths that have led the ERJ to reach its current situation.

Founded in 1988, the ERJ is now in its 21st year, a symbolic age that represents the starting point of adulthood for many of us. Indeed, the ERJ has gained in maturity and respectability, with a steady increase in the impact factor over the last 5 yrs [8]. The numbers of papers viewed via, and/or downloaded from, the ERJ website [10] have also made a big jump forward, with the number of monthly hits averaging 500,000. This gain in popularity is certainly due to an increase in the scientific quality of the papers published, which is thanks to the rigorous selection made by all previous Chief and Associate Editors. However, none of the ERJ's recent evolutions could have been achieved without the strong support of the ERS Publications office in Sheffield (UK).

Talking about work places, one question that may be asked is "do the current Chief Editors live and work in Sheffield too?" We all know the obvious answer! The answer can also be easily guessed by anyone realising how modern electronic communication can turn Europe and the rest of the world into a small place where information can be sent and received within seconds, while we are at work, at home, or even in a quiet

\footnotetext{
*Dept of Cardiopulmonary Medicine, Cochin Hospital, University Paris Descartes, Paris, France. ${ }^{*}$ Dept of Internal Medicine, Medical School, University of Genoa, Genoa, Italy.

STATEMENT OF INTEREST: A statement of interest for $\mathrm{V}$. Brusasco can be found at www.erj.ersjournals.com/misc/statements.shtml

CORRESPONDENCE: A.T. Dinh-Xuan, Service de Physiologie-Explorations Fonctionnelles, Hôpital Cochin, 27 rue du faubourg Saint-Jacques, 75104 Paris, France. Fax: 33 158412345. E-mail: anh-tuan.dinh-xuan@cch.aphp.fr
}

corner of the charmless waiting rooms of international airports or domestic railway stations. With such convenient tools, the number of electronic messages sent between Sheffield, Paris and Genoa sometimes reaches several dozen if not hundreds, during rush hours on busy days, enabling the Associate Editors and us to circulate questions, proposals, ideas and make final decisions relating to important issues.

Communication speed not only matters to the Chief Editors and the Publications office, but also to all members of the Editorial Board. As a matter of fact, we are unanimously convinced that the speed of information exchange is inversely related to reviewing turnaround times. Editors, and authors alike, want the reviewing process to be fair, quick and reliable. So, it is easy to understand and share the frustration an author can have when waiting months for a decision, which will eventually result in a negative outcome and, even worse, with exceedingly brief editorial comments. However, authors can often be pleasantly surprised by a swift and positive decision from the Editors, only a few weeks after submission of their papers. In all fairness, we have to say that most manuscripts submitted to us will be returned to their authors without the possibility for revision, as the acceptance rate has now been set at approximately only $15 \%$. With respect to the majority of papers that do not reach sufficiently high priority for acceptance, the decision for rejection needs to be made with all the necessary esteem and consideration for those who have trusted the ERJ with the submission of their work. Albeit difficult, the negative decision would probably be easier to accept when made quickly and fairly. Fairness can even be greater when the lengthier reviewing time is justified by detailed analysis, which requires time, and constructive comments from the reviewers and editors, therefore enabling subsequent improvement in the quality of the manuscript and the chance for it to be published in another journal. However, such finely tuned editorial work cannot be achieved without the commitment of the Associate Editors who help us with their infallible collaboration and unerring sense of evaluation. Working together in a modern environment with appropriate communication tools to better serve respiratory medicine, scientists and healthcare professionals will be our guiding principle.

In essence, the achievements of the first 20 yrs of the European Respiratory Journal's life appear to be strong enough to give us reasonable confidence in being able to fulfil the expectations of the ERS, which decided to grant us this important position. The resources of the ERS Publications office and the excellence 
of the Editorial Board are sufficiently important to reinforce our honest ambition and feed our unshakable hope of the European Respiratory Journal maintaining its standard and continuing its evolution over the next 4 yrs.

\section{REFERENCES}

1 Quanjer PH. The society is coming of age. Eur Respir J 1988; 1: 2-4.

2 Vermeire P. The ERJ two years later. Eur Respir J 1993; 6: 11-12.

3 Sterk PJ, Rabe KF. You've got mail: erj@lumc.nl. Eur Respir J 2003; 21: 1-2.
4 Rabe KF, Sterk PJ. Rapid, reliable and responsive: for whom? Eur Respir J 2004; 23: 1-2.

5 Sterk PJ, Rabe KF. Serving researchers, the impact factor and other conflicts of interest. Eur Respir J 2005; 25: 3-5.

6 Rabe KF, Sterk PJ. Editing the ERJ: an observational study. Eur Respir J 2006; 27: 1-2.

7 Sterk PJ, Rabe KF. What else can you expect at www.erj. ersjournals.com? Eur Respir J 2007; 29: 1-3.

8 Rabe KF, Sterk PJ. Five good reasons to read (and cite) the ERJ. Eur Respir J 2008; 31: 1-2.

9 Rabe KF, Sterk PJ. Your 10,000 manuscripts. Eur Respir J 2008; 32: 1425.

10 European Respiratory Journal. http:/ / erj.ersjournals.com/ 